\title{
Mathematics Literacy: An Australian Perspective and Experience
}

\author{
Allan Leslie White \\ SEAMEO Regional Centre for QITEP in Mathematics \\ allan.white6@gmail.com
}

\begin{abstract}
A brief listing of five different types of mathematical literacy is provided. The definition used by the Program for International Student Assessment (PISA) is selected and some brief remarks are provided on this program. The performance of Australian students is examined which shows that at the beginning of the new century 2000, Australian educators were feeling comfortable and reasonably satisfied with student performance but by 2016 there was great concern over a consistent decline. The reasons for this decline are briefly discussed with the focus on Australian governmental policies that followed the directions of reform in the United States and Great Britain, and what has been labelled GERM. Current policies have been tried and failed and it is time to look for alternatives. While it is not wise to just copy the programs and policies of another country rather than adapt them due to differences in culture, population diversity, and other factors, nevertheless countries such as Finland can offer alternative paths to be explored. In Australia's case it would also seem to be unwise to adopt policies and programs of countries who perform worse than it.
\end{abstract}

Keywords: mathematical literacy, PISA, GERM, TIMSS, high-stakes testing, Finland, market-driven policies, MaRWA, NAPLAN

\section{Introduction}

The term mathematical literacy raises many issues and questions for educators and researchers such as: (1) What are the different views of mathematical literacy and how are they related to, or distinct from, other similar views such as numeracy, quantitative literacy, mathematical competence, mathematical proficiency? (2) Why is mathematical literacy on the agenda of mathematics education? (3) How is mathematical literacy implemented in education programs and curricula? (4) Is it meant to be a separate subject or an integrated part of mathematics and what teaching and learning activities and materials exist? (5) How does a focus on mathematical literacy influence pre-service and in-service teacher education? (6) How is mathematical literacy situated in comparative studies in mathematics education nationally or internationally? (7) How is mathematics education being influenced by literacy based studies? (8) What new and valuable outcomes can be gained from focusing on mathematical literacy instead of or in addition to traditional mathematical knowledge and skills? (9) What problems or pitfalls may result from such a focus? (10) What are the likely desirable or undesirable changes of practices in mathematics education resulting from a mathematical literacy focus? This paper will not attempt to answer all these questions. Instead, it will begin by selecting a definition from among many and then focus the discussion upon the Australian experience.

There has been an expanding body of research and scholarship focused on school literacy and numeracy. Within this expansion, the term 'mathematical literacy' has emerged. Jablonka (2003) attempted to define the term, making the distinction that was wider than mathematical knowledge because it included an individual's ability to use and apply the 
mathematical knowledge to a specific context. It is literacy for something, and she categorized five different types of mathematical literacy.

Her list includes mathematical literacy for developing human capital that looked at the world through mathematical eyes, emphasizing higher order thinking, real world problems, and underpinned by critical citizenship for participation in public and economic life. Organization for Economic Co-operation and Development (OECD) (2006) suggests that the Program for International Student Assessment (PISA) is intended to estimate and compare the stock of human capital. PISA (OECD , 2006) defines mathematical literacy as an "individual's capacity to identify and understand the role that mathematics plays in the world, to make well-founded judgments, and to engage in mathematics in ways that meet the needs of that individual's current and future life as a constructive, concerned, and reflective citizen" (p. 72). As a consequence of this definition, PISA mathematics units usually begin with a description of a real life context and it is here that a difficulty arises in making the contexts comparable across differing countries. Irrespective of the large body of criticism around their validity in making cross country comparisons, the results of the international comparative studies have contributed to a growing public interest in mathematical literacy.

Second on Jablonka's (2003) list is mathematical literacy for cultural identity, where mathematics is seen as a pan-cultural universal activity for representing and explaining the natural world and that all cultures have developed some kind of mathematical capital.

A third list inclusion is mathematical literacy for social change where it becomes a process of developing a critical consciousness for re-interpreting parts of reality and pursuing different realities. This recognizes attempts to avoid privileging Western academic mathematical knowledge by incorporating ethno-mathematical and everyday knowledge into school mathematics.

A fourth inclusion is mathematical literacy for environmental awareness which is a process for developing skills and attitudes for understanding the interrelationships between humans and the natural environment.

In the light of global environmental problems and scientific fallacies, which are conceived as partly caused by technological interventions based on traditional mathematics, a few writers consistently suggest that mathematics itself should be developed into more suitable alternative forms (Jablonka, 2001, p. 97).

The final inclusion is mathematical literacy for evaluating mathematics where all applications of mathematics are seen as value driven and thus the school curriculum requires criteria for evaluation. The curriculum aims to produce a 
and to participate in political discussions that draw on statistics and results from mathematical models (Jablonka, 2001, p. 97).

For the purposes of this paper, only one will be adopted and briefly examined in relation to the Australian experience and that is the definition used by PISA.

\begin{abstract}
Mathematical literacy is an individual's capacity to formulate, employ and interpret mathematics in a variety of contexts. It includes reasoning mathematically and using mathematical concepts, procedures, facts and tools to describe, explain and predict phenomena. It assists individuals to recognise the role that mathematics plays in the world and to make the well-founded judgments and decisions needed by constructive, engaged and reflective citizens (OECD, 2016, p. 13).
\end{abstract}

In Australia, the term numeracy is often used synonymously with mathematical literacy, although in fact its meaning ranges from a narrow ability with number, ability to use mathematics in different situations; ability to understand the meaning of mathematics (Willis, 1991).

\title{
Australia's Performance
}

Having chosen to confine mathematical literacy to Jablonka's (2003) category one fits with the definition of the PISA which claims to be an international assessment of the skills and knowledge of 15-year olds.

\begin{tabular}{|c|c|c|c|c|c|}
\hline PISA 2000 & PISA 2003 & PISA 2006 & PISA 2009 & PISA 2012 & PISA 2016 \\
\hline Reading literacy & Reading literacy & Reading literacy & Reading literacy & Reading literacy & Reading literacy \\
\hline $\begin{array}{c}\text { Mathematical } \\
\text { literacy }\end{array}$ & $\begin{array}{l}\text { Mathomatical } \\
\text { literacy }\end{array}$ & $\begin{array}{l}\text { Mathematical } \\
\text { literacy }\end{array}$ & $\begin{array}{l}\text { Mathematical } \\
\text { literacy }\end{array}$ & $\begin{array}{c}\text { Mathematical } \\
\text { Iiteracy }\end{array}$ & $\begin{array}{c}\text { Mathematical } \\
\text { litoracy }\end{array}$ \\
\hline Scientific literacy & Scientific literacy & Scientific literacy & Scientific literacy & Scientific literacy & Scientific literacy \\
\hline Major domain & Minor domain & & & & \\
\hline
\end{tabular}

Figure 1. Cycles of PISA and the major and minor domains of assessment for each cycle (Thomson, De Bortoli, \& Underwood, 2016, p. Xv).

Member countries of the OECD conduct this program at three year intervals since 2000. The PISA website (www.oecd.org/pisa) is the official gateway to information and most of the references used in this paper and many other PISA reports can be downloaded. There were 72 countries and economies that participated in PISA 2015, including 35 OECD countries and 37 partner countries or economies 


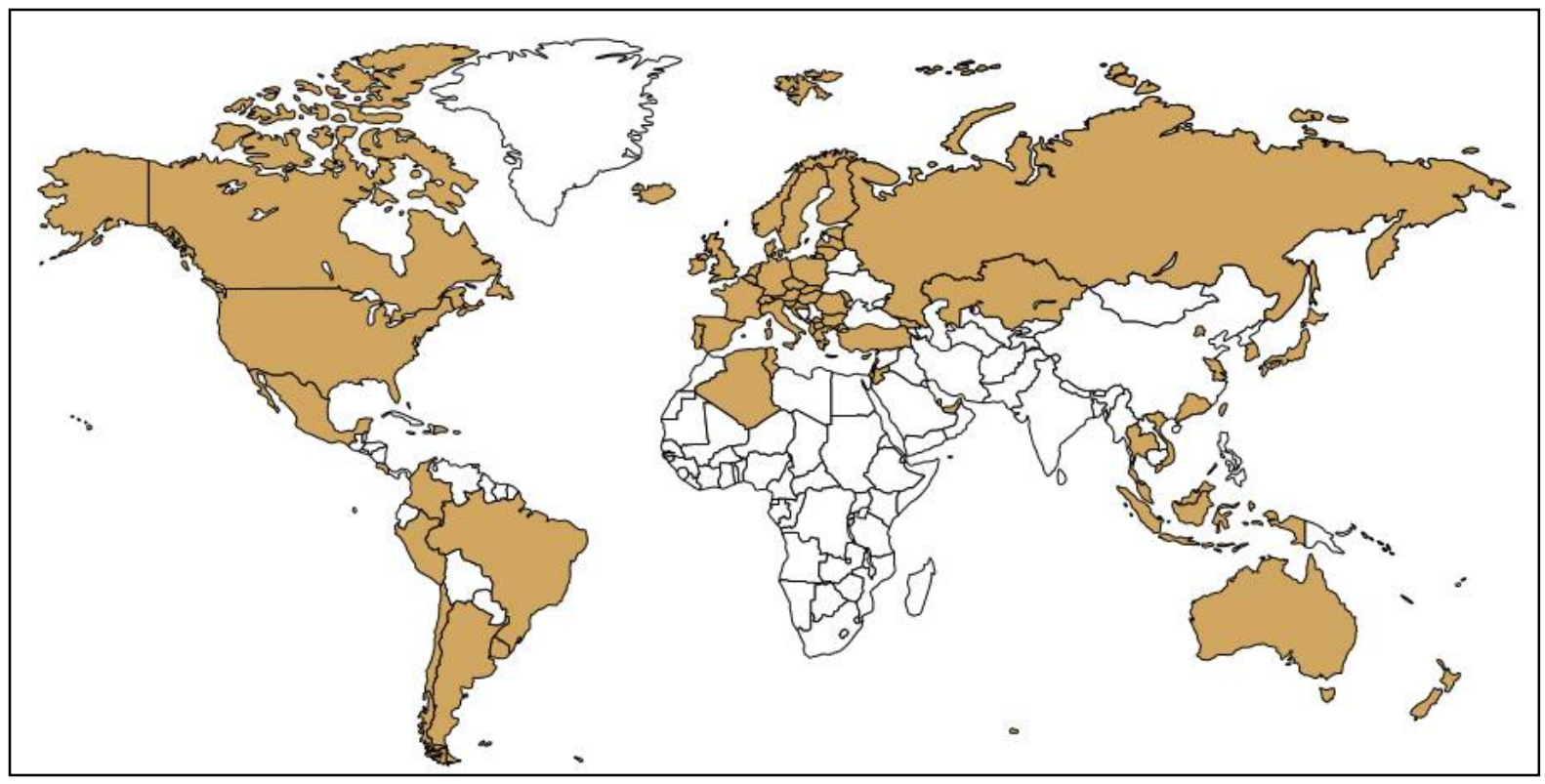

Figure 2. Countries and economies that participated in PISA 2015 (Thomson, De Bortoli, \& Underwood, 2016, p. xviii)

PISA mathematical literacy is organized into three broad components: (1) the situations and contexts in which problems are located and sources of stimulus material, (2) the mathematical content to which different problems and questions relate, and (3) the mathematical competencies connected to the real world problem solving required. Of note is that Pearson which is one of the biggest textbook publishers and providers of professional development services for teachers around the world has been contracted by OECD to develop the 2018 PISA test (Lingard, Sellar, Hogan, \& Thompson, 2017). The three components are shown in Figure 3.

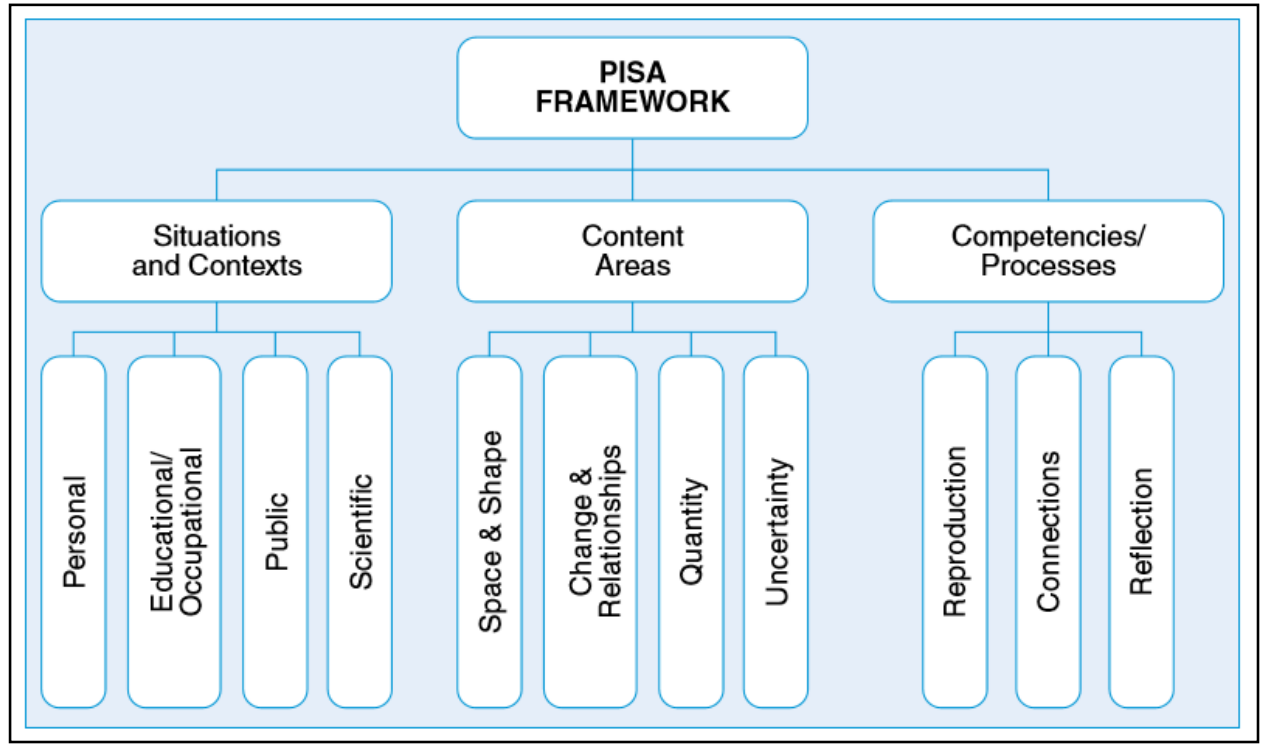

Figure 3. The components of the mathematical literacy framework (Thomson, Hillman, \& De Bortoli, 2013, p. 8) 
At the beginning of the new century 2000 Australian educators were feeling comfortable and reasonably satisfied with student performance as indicated by international studies and they were unprepared for both a decline in performance and a domestic political war that erupted involving state and federal bodies as the century progressed.

In the early twenty-first century Australia's 15-year old students performed very well on the mathematical literacy scales in terms of the knowledge and skills investigated by the OECD in its PISA for 2000 and 2003 (OECD 2000, 2004). In addition, the Trends in International Mathematics and Science Study (TIMSS) for 1994/5 and for 2002/03 revealed that Australian Year 8 students' achievement in mathematics was significantly higher than the international average in all content areas considered (Thomson \& Fleming, 2004).

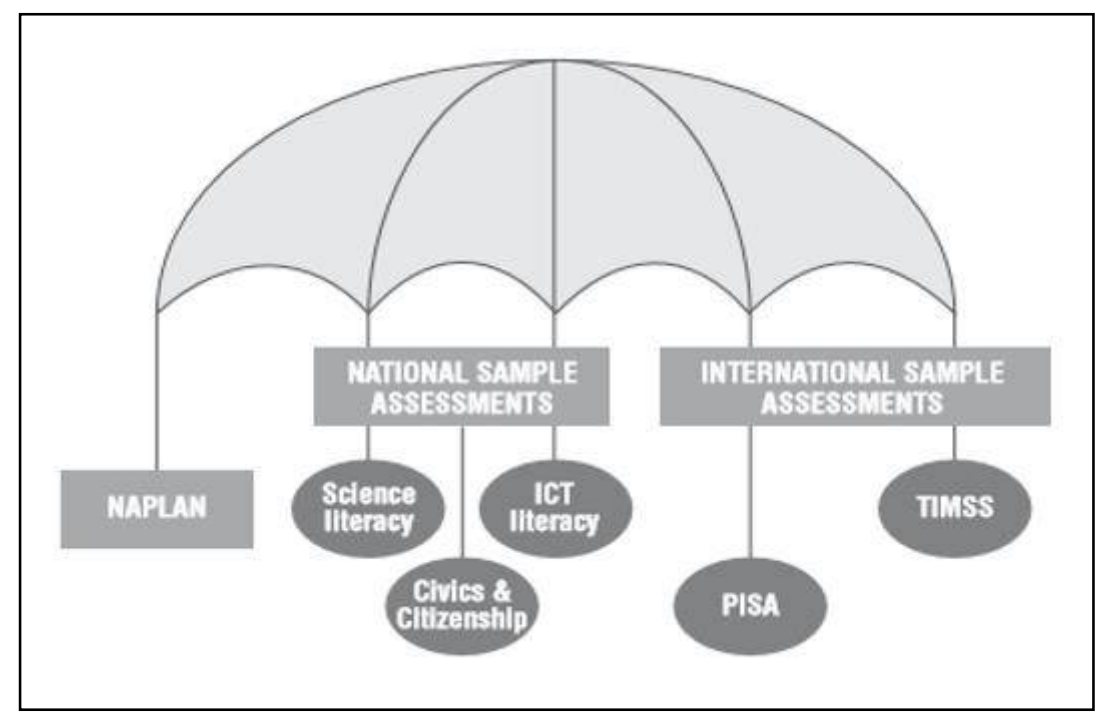

Figure 4. Components of the Australian national assessment program (Thomson, Hillman, \& De Bortoli, 2013, p. 2)

In the lead up to 2015 PISA, Australia had declared its ambition to be within the top five countries in PISA by 2025. So serious was it about this ambition that the Australian Government had incorporated it into the Australian Education Act 2013, then PISA became an integrated part of an Australian national assessment program which had greatly centralized the curriculum, introduced corporate management models for educational change, and introduced a national basic skills testing program, National Assessment Program Literacy and Numeracy (NAPLAN).

If the focus now jumps ahead to the PISA 2015 when the results were launched on 6 December 2016, the situation in Australia had changed. The results confirmed what had been a steady decline in the performance of Australian students on international comparison testing programs, and pointed to the failure of the educational policies introduced from 2000 onwards. 
The results displayed in Figure 5 illustrate the decline. PISA warned that Australia's previous ranking as a high-equity and high-quality education system was in jeopardy.

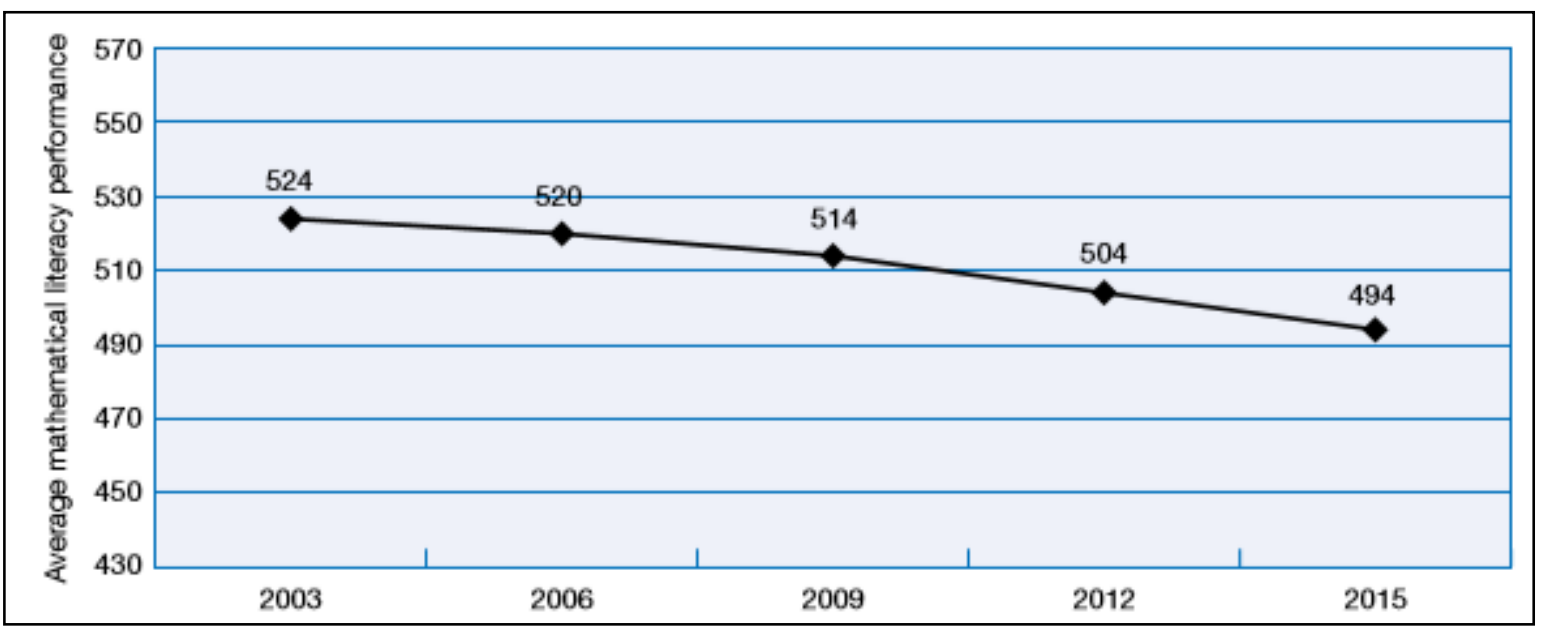

Figure 5. Australia's mathematical literacy performance on PISA (Thomson, De Bortoli, and Underwood, 2016, p. 21)

Andreas Schleicher, the education chief of the OECD warned Australia that it needed to take the decline seriously. Of equal concern was those students in the lowest achievement bands which included a disproportionate number of indigenous students. Students in the highest socioeconomic quartile achieved an average score of 541 points, which was 86 points (or around three years of schooling) higher than the average score of 455 points for students in the lowest socioeconomic quartile. The next section will briefly examine reasons for Australia's slide from a comfortable position to one of concern over a period of fifteen years.

\section{What Contributed to the Decline?}

The Howard years in government spanned 1996 till 2007 and during those years there was an increase in the politicizing of education and education funding and an increasing move to provide better support for private schools arguing there was a need to provide parents with more choice. In Australia the states provided the majority of funding to government schools with some federal input, whereas the reverse happened for private and independent schools. The Labor opposition argued that this was support for the elite at the expense of the disadvantaged students although both federal and state governments increased resources for the independent sector.

The Rudd-Gillard-Rudd years in government 2007-2013 continued the trend of using education as a political issue. One of the Rudd Government's key proposals in the 2007 election campaign was the implementation of the Building the Education Revolution (BER). This was to include the "digital revolution" with the provision of computers for every secondary school student in Years 9-12 and the implementation of a national curriculum. In response to the Howard years, a report into the funding of schools both government and private was completed 
and is known as the Gonski Report. One issue it highlighted was that disadvantaged schools required greater support and resources. This report has been hotly debated between the states and federal government and between Labor and the conservative-liberal coalition. Also, scholarships for disadvantaged students and funding for childcare became areas of savage political contention.

NAPLAN was introduced as a series of tests focused on basic skills that were administered annually to Australian students in Years 3, 5, 7, and 9. These standardized tests assessed students' reading, writing, language (spelling, grammar, and punctuation) and numeracy and were administered by the Australian Curriculum, Assessment and Reporting Authority (ACARA). The data obtained from the NAPLAN tests are shown on the My School website which shows all schools' average performance against other schools in the country. It claimed to provide parents with information in order to compare schools and thus providing them with greater choice. However, many critics claim that while NAPLAN testing was designed to improve the quality of education young people receive in Australia, its implementation and uses and misuses meant that it undermined quality education and did harm that was not in the best interests of Australian children. Of note in the state of New South Wales since 2012 under two agreements with the NSW Educations Standards Authority, Pearson has been responsible for printing and distributing NAPLAN tests, overseeing the marking process and reporting the results.

Under the Labor, the Australian Institute for Teaching and School Leadership (AITSL) was formed to develop and monitor national teaching standards and teacher accreditation. This initiative has generally been well received as a strategy for improving the professionalism of the teaching work force. In the mid of 2010, Gillard who had been education minister replaced Rudd as leader and was then replaced by Rudd in 2013 and shortly after the Labor party lost the election.

The Abbot - Turnbull government (2013 - current) has adjusted the existing programs to meet its political aims and has recently announced changes to the funding of childcare by the Education Minister Birmingham which includes the testing of children, and a revised Gonski model.

It is possible to summarize the directions of federal and state educational policies since the start of the new century that have accompanied the decline in Australia's international student performance:

- increased politicization of education across Australia;

- greater centralization of the curriculum and adoption of business management models; 
- major political parties unable to compromise and collaborate;

- greater funding of independent and private schools and failure to implement Gonski's needs-based funding of all schools;

- increase in the amount of testing and reporting of student performance on basic skills;

- increasing inequality and less emphasis on reducing educational disadvantage; and

- a loss of autonomy by teachers and schools and a greater administration load.

Australia has a history of following trends in education that have arisen in the United States and/or Great Britain in spite of mostly performing better than these two countries on international assessment studies such as TIMSS and PISA.

Sahlberg (2011) the Director General of the Centre for International Mobility and Cooperation at the Finnish Ministry of Education used the acronym GERM (Global Education Reform Movement) to refer to the education reforms and policy-making procedures of US and Great Britain and other western countries that employ "management models from the business world, such as test-based accountability, merit-based pay, and data-driven administration" (p. 99). Australian and other researchers feel the movement is more accurately described as GERMs (Lingard, Sellar, Hogan, \& Thompson, 2017).

Sahlberg (2011) listed five features of GERM: (1) standardization in education, (2) increased focus on core subjects in the curriculum, (3) prescribed curricula, (4) management models from the corporate world, and (5) high-stakes accountability policies for schools. Sahlberg (2011) claimed that GERM leaders choose the wrong drivers for change: by emphasizing teacher accountability over teacher professionalism, by targeting individual teacher quality over encouraging collegiality, technology vs. pedagogy, and fragmented strategies vs. systems thinking. Australia has embraced these features of GERM in spite of research that shows they are not working (the United States is consistently below Australian PISA performance). Hargreaves (2011, p. xv) claims show that:

\footnotetext{
... the United States, like many other Anglo-American nations, has epitomized Einstein's definition of madness: keep doing the same thing while expecting to get a different result.
}

Professor Yong Zhao, the leading American expert on educational reform in China and Southeast Asia, is gentler in his remarks. However, he points out that China, the leading economic competitor of the United States, is decentralizing its curriculum, diversifying its assessment, and encouraging local autonomy and innovation. Meanwhile, Zhao concludes, while China is decentralizing and Singapore is promoting a creative environment characterized by the principle of 'Teach Less, Learn More' the United States has been stubbornly "moving toward authoritarianism, letting the government dictate what and how students should learn and 
what schools should teach" (Zhao, 2009, p. 40). Zhao's comments resonate with the education directions in Australia which is certainly showing the effects of GERMs.

Even the last American president Barack Obama was worried about the assessment regime and offered three principles that should be fulfilled in order to be worthwhile.

1. Students should only take tests that are worth taking. Tests that are of high quality and aimed at good instruction while ensuring students are on the right track.

2. Tests should not occupy too much classroom time, or crowd out teaching and learning. Tests should enhance the teaching and learning process.

3. Tests should be just one source of information to be used alongside classroom work, surveys, and other factors, to give us a comprehensive view of student progress.

So, after studying the declining performance of Australian students, what should the educational authorities do to achieve their ambition to be within the top five countries in PISA by 2025 ?

\section{Where to Now?}

If Australia is to lift performance on PISA and TIMSS in the future, a possible direction may be to scrutinize the policies and practices of other successful countries rather than the unsuccessful ones. Finland has been highlighted as a model to follow whereby "the Finns transformed their educational system from mediocre in the 1980s to one of the models of excellence today (Sahlberg, 2011, p. 1). Yet education researchers (Hatano \& Inagaki, 1998; White, 2013) have highlighted problems with just adopting other country programs rather than adapting them to local contexts because "pedagogical methods are culturally embedded, and transplanting them from one culture to another is not always feasible" (Hatano \& Inagaki, 1998, p. 101). There are considerable differences between Finland and Australia to make direct copying unwise. For example, Finland is a small nation in size with a homogeneous population, a small immigration intake whereas Australia is a large continent with a multi-cultural population and with a large immigration intake. However, these warnings do not prevent Australia from learning from the Finns. For example, instead of blindly following the top-down, test-based accountability, the use of market competition between schools, the use of private sector managerial practices, and the increasingly standardized curriculum that focuses on literacy and numeracy, it is possible "that a consistent focus on equity and cooperation ... can lead to an education system where all children do well" (Sahlberg, 2011, p. 9). At the very least, Finland provides some alternative directions for consideration as current policies are increasing the inequality among Australian students.

Perhaps the components of the Australian national assessment program need to be revisited. Is it educationally sound to include PISA and TIMSS as key components? This also has implications for the extent and character of commercialization of Australian public 
schooling which is beyond the scope of this paper and can be found elsewhere (see Lingard, Sellar, Hogan, \& Thompson, 2017).

Is the influence of PISA and TIMSS beneficial or harmful? Perhaps the Australian government could lessen the policy focus upon PISA and other international assessment programs and neutralize their influence upon education in Australia. Kilpatrick (2013, p. 793) in the Third International Handbook of Mathematics Education does not feel their influence has been thoroughly investigated:

Studies such as TIMSS and PISA are extensively reported in the media in many countries, but any effects on school mathematics in those countries have yet to be documented.

There are many who doubt that international comparisons are relevant or even reliable in what they claim to show and do not include the full range of outcomes produced by schooling. Skill sets that include interpersonal, spatial, and creative skills are becoming increasingly important in the current business world.

\footnotetext{
One point of view is that academic achievement tests, such as the Programme for International Student Assessment (PISA), Trends in International Mathematics and Science Study (TIMSS), and Progress in International Reading Literacy Study (PIRLS) focus on areas too narrow to capture the whole spectrum of school education, and ignore social skills, moral development, creativity, or digital literacy as important outcomes of public education for all (Sahlberg, 2011, p. 8).
}

$\mathrm{Wu}(2008)$ quantified the effects of school curricula on the results by measuring what she called the content advantage to show how a country's national performance on international tests is affected by the alignment of its curriculum with the PISA assessment criteria. Australian students consistently do well in the assessment items involving chance and the interpretation of data as these topics are well represented in the Australian curriculum.

A final criticism involving the nature of the items revolves around the real world context. The criticism is that the PISA ambitions of testing real-life skills and competencies in authentic contexts are by definition impossible to achieve (Sjøberg, 2007). Add to this is the difficulty in finding contexts that are common to a variety of participating countries.

It is beyond the scope of this paper to do justice to the large amount of research evidence which questions the value of these international assessment programs in terms of individual countries but also points to why it is not fair, constructive or valid to use them to compare countries. To obtain maximum value for the great cost of participating, a country might well be advised to participate in the programs but insist that their data was not aggregated and used in any comparative reports. Or they might develop their own more localized program as SEAQiM is currently doing by constructing a regional assessment program for Southeast Asian called Mathematics Regional Wide Assessment (MaRWA). 


\section{Conclusion}

This paper has briefly discussed why the Australia education system is in decline as evidenced by international and national assessment programs. The challenge for policymakers, schools, and teachers is how to respond to increasing pressure to lift test results on PISA, TIMSS, and NAPLAN testing programs, while also addressing systemic inequality in order to ensure that every Australian student is given access to a meaningful education. Equitable funding of schools, including redistribution to schools serving disadvantaged communities, remains a pressing policy issue in Australia.

There are lessons to be learned by other countries in observing the Australian experience and that is to avoid GERMs or to put it more bluntly do not adopt policies and programs from countries that are performing worse than you.

\section{References}

Jablonka, A. (2003). Mathematical Literacy. In A.J. Bishop, M.A. Clements, C. Keitel, J. Kilpatrick, \& F.K.S. Leung (Eds.), Second international handbook of mathematics education (pp. 75-102). Dordrecht, the Netherlands: Kluwer Academic Publishers.

Hargreaves, A. (2011). Foreword: Unfinished business. In P. Sahlberg, Finnish lessons (pp. xV-Xx). New York: Teachers College Press.

Hatano, G., \& Inagaki, K. (1998). Cultural contexts of schooling revisited: A review of the learning gap from a cultural psychology perspective. In S. G. Paris, \& H. M. Wellman (Eds.), Global prospects for education development, culture and schooling (pp. 79104). Washington D.C.: American Psychological Association.

Kilpatrick, J. (2013). Introduction to section D: International perspectives on mathematics education. In M.A. Clements, A.J. Bishop, C. Keitel, J. Kilpatrick, \& F.K.S. Leung (Eds.), Third international handbook of mathematics education (pp. 791-795). New York: Springer.

Lingard, B., Sellar, S., Hogan, A., \& Thompson, G. (2017). Commercialisation in public schooling (CIPS). Sydney: New South Wales Teachers Federation.

Organization for Economic Co-operation and Development (OECD). (2002). PISA 2000 technical report. Paris: OECD.

Organization for Economic Co-operation and Development (OECD). (2004). Learning for tomorrow's world. Paris: OECD.

Organization for Economic Co-operation and Development (OECD). (2006). Assessing scientific, reading and mathematical literacy: A framework for PISA 2006. Retrieved from http://www.pisa.oecd.org/dataoecd/63/35/37464175.pdf 
Organization for Economic Co-operation and Development (OECD). (2016). PISA 2015 assessment and analytical framework: Science, reading, mathematics and financial literacy. Paris: Author.

Sahlberg, P. (2011). Finnish lessons. New York: Teachers College Press.

Stacey, K. (2011). The PISA view of mathematical literacy in Indonesia. Indonesian Mathematics Society Journal of Mathematics Education, 2(2), 95-126.

Sjøberg, S. (2007). PISA and "real life challenges": mission impossible? In S.T. Hopmann, G. Brinek, \& M. Retzl, (Eds.), PISA according to PISA, does PISA keep what it promises? (pp. 1-18). Wien: LIT Verlag.

Thomson, S., \& Fleming, N. (2004). Summing it up: Mathematics achievement in Australian schools in TIMMS 2002, (TIMMS Australia Monograph No 6). Camberwell, Victoria: ACER.

Thomson, S., Hillman, K., \& De Bortoli, L. (2013). A teacher's guide to PISA mathematical literacy. Camberwell, Victoria: ACER Press.

Thomson, S., De Bortoli, L., \& Underwood, C. (2016). PISA 2015: A first look at Australia's results. Camberwell, Victoria: ACER Press

Thomson, S., De Bortoli, L., \& Underwood, C. (2017). PISA 2015: Reporting Australia's results. Retrieved from: http://research.acer.edu.au/ozpisa/22

White, A. L. (2013). Literacy and mathematics. In R. Gregson (Ed.), Literacy across the curriculum (pp. 34-51). Illinois, USA: Common Ground Publishing.

Willis, S. (1990). Numeracy and society: the shifting ground. Being numerate: what counts (Ed.). Melbourne: Australian Council for Educational Research.

Wu, M. (2008). A Comparison of PISA and TIMSS 2003 achievement results in mathematics and science. Paper presented at the $3^{\text {rd }}$ IEA Research Conference, Taipei.

Zhao, Y. (2009). Catching up or leading the way: American education in the age of globalisation. Alexandria, VA: ASCD. 